\title{
Comparison of Quasi-Static and Dynamic Compressive Response of E-Glass/Polyester-CNF Nanocomposites
}

\author{
Mohammad Kamal Hossain ${ }^{1 *}$, Muhammad Enayet Hossain ${ }^{2}$, Mahesh Hosur ${ }^{3}$ and Shaik Jeelani ${ }^{3}$ \\ 1. Department of Mechanical Engineering, Tuskegee University, Tuskegee, AL 36088, USA \\ 2. Department of Mechanical Engineering, City College of City University of New York, New York, NY 10031, USA \\ 3. Department of Materials Science and Engineering, Tuskegee University, Tuskegee, AL 36088, USA
}

\begin{abstract}
Quasi-static and dynamic compression response of conventional and 0.1-0.3 wt\% CNF (Carbon nanofiber) incorporated glass fiber reinforced polyester composites (GRPC) were measured. A high intensity ultrasonic liquid processor was used to infuse CNF into the polyester matrix which was then mixed with a catalyst using a high speed mechanical agitator. SEM (Scanning electron microscopy) revealed best dispersion of CNF in the $0.2 \mathrm{wt} \%$ CNF-loaded polyester matrix. Quasi-static (at low strain rate, $10^{-3} \mathrm{~s}^{-1}$ ) compression tests performed on conventional and 0.1-0.3 wt $\%$ CNF-loaded GRPC revealed $43 \%$ and $60 \%$ increase in strength and modulus, respectively, over the conventional sample. High strain rate compressive strength and modulus of nanophased GRPC were characterized using SHPB (Split Hopkinson pressure bar). At strain rates of 550, 700, and $800 \mathrm{~s}^{-1}$ compressive strength and modulus were observed to be enhanced by $31 \%$ and $64 \%$, respectively, over static values. Fracture morphology studied by both OM (Optical microscopy) and SEM revealed fiber kinking and shear fracture at low strain rates and fiber-matrix debonding, delamination, and fiber breakage dominating at high strain rates. The extent of damage was more pronounced in the conventional composite compared to nanophased ones.
\end{abstract}

Key words: CNF (Carbon nanofiber), sonication, fiber-reinforced composites, VARTM (Vacuum assistant resin transfer molding), high strain rate.

\section{Introduction}

FRPs (Fiber reinforced polymeric composites) have become attractive structural materials in aerospace, marine, defense, automobile, transportation, and sporting goods industries as well as in civil engineering structures due to their high specific strength and stiffness to weight ratio [1]. However, these composites have some limitations linked to the matrix dominated properties which could often limit their extensive use in various applications. In particular, FRPs' through-the-thickness performance lacks some of the most demanding physical and mechanical property requirements for structural applications. Incorporation of inorganic fillers in the composites were found to be effective in improving mechanical, thermal, and other physical properties of

*Corresponding Author: Mohammad Kamal Hossain, Ph.D., research fields: materials and design. these materials [2-4]. Many composite structures might be subjected to static and dynamic loading situations that include quasi-static and high strain rate compressive loading.

Micron size fillers (10-20\% by volume) may enhance properties of conventional fiber reinforced polymeric composites significantly. Processing of composites often becomes difficult at such high particle volume fractions due to the higher density of the resulting material [5]. However, it has been established that the addition of a small amount of nanoparticles $(<5 \mathrm{wt} \%)$ to a matrix can enhance mechanical, thermal, and barrier properties of the pure polymer matrix without compromising the weight or processability of the composite [6, 7]. The CNF (Carbon nanofiber) has proved to be an effective reinforcement both in neat polymer as well as their FRPs due to its excellent mechanical, thermal, and 
electrical properties. It offers great promise to improve the weak properties of the composites in the thickness direction and impart multi-functionality without substantial weight addition to FRPs [2, 3]. Higher surface area, especially when reactive, is one the most promising characteristics of nanoparticles due to their ability of creating better interface in a composite. Contribution made by the interphase modified by low nanofiller loading provides possibilities of enhanced performance by influencing the properties of the matrices. A significant improvement in the tensile performance of polypropylene composites in terms of stiffness, strength, and toughness was reported with a low nanosilica content of about $0.5 \%$ by volume [8].

Uniform dispersion of optimum amount of nanoparticles in the matrix is one of the most important factors in fabricating $\mathrm{CNF}$ infused composites. Good dispersion of nanoparticles can be achieved through processing techniques such as solution blending, shear mixing, in situ polymerization, ultrasonic cavitation, and high pressure mixing [4, 9-13].

At higher strain rates, both failure stress and modulus increase nonlinearly with increasing strain rates. Rising strain rates reduce the molecular mobility of polymer chains resulting in stiffening of the material [14]. It has been reported that dynamic strength increases and strain to failure decreases with increasing strain rates [15]. The compressive mechanical behavior of nanoparticle modified epoxy materials has been investigated over a wide range of strain rates $\left(0.001-3,500 \mathrm{~s}^{-1}\right)$ and high strength was observed especially at high strain rates [16]. Hosur et al. [17] documented considerable increase in the dynamic compression peak stress compared to a static loading whereas strain at peak stress was lower by $35-65 \%$ in woven carbon/epoxy composites. Compressive modulus and failure strength of woven glass fiber/SC-15 composites in the thickness direction in strain rate regimes of $10^{-4}$ to $10^{-3} \mathrm{~s}^{-1}$ were found to be strain rate sensitive showing increasing trend with increasing strain rates. Failure occurred via matrix fracture, delamination, and particle pull-out [18].

Both static and dynamic compressive strengths of $\mathrm{SiO}_{2}$ filled epoxy nanocomposites were found to be higher than those of neat epoxy [19]. Tsai and Huang [20] observed that linear portions of stress and strain curves were not affected considerably by strain rates. However, yield stresses increased with the augmentation of strain rates in case of dry nylon 6-clay nanocomposites. The dynamic response of polyester $/ \mathrm{TiO}_{2}$ nanocomposites under high strain rate $\left(2,000 \mathrm{~s}^{-1}\right)$ compression loading revealed that an addition of nanoparticles contributed to a moderate stiffening effect [21]. However, there was no significant effect on ultimate strength. Both neat and nanophased polypropylene showed strain rate-sensitivity and their yield strength, modulus, and tensile strength increase with the strain rate [22]. It has been observed that the yield stress of the melt mixing polypropylene organoclay nanocomposites increases with increasing strain rate. However, the degree of enhancement depends on the concentration of organoclay and its extent of exfoliation throughout the composite [23].

To the best of authors' knowledge, studies on the effect of $\mathrm{CNF}$ on the high strain rate response of woven E-glass/CNF-polyester nanocomposites have not been performed. Hence, the objectives of this study are to characterize conventional and nanophased composite materials under such loading situations and compare their responses. Conventional and CNF filled glass-fiber reinforced polyester (GRP) laminates using 35 plies of woven E-glass were fabricated using the VARTM (Vacuum assistant resin transfer molding) process. Quasi-static and high strain rate mechanical compressive properties were characterized using MTS (Material testing system) and SHPB (Split Hopkinson pressure bar), respectively. The fracture morphology of tested specimens was examined under SEM 
(Scanning electron microscopy) and OM (Optical microscopy).

\section{Experimental}

\subsection{Materials Selection}

Commercially available B-440 premium polyester resin and styrene (US Composite Inc., West Palm Beach, Florida, USA), heat treated PR-24 CNF (Pyrograf Products, Cedarville, Ohio, USA) and plain weave E-glass fiber (Fiberglasssite, Kingsville, Maryland, USA) were used as matrix, thinner, nanoparticle, and reinforcement, respectively, in the current study. Polyester resin contains two components: part-A (polyester resin) and hardener part-B (MEKP- methyl ethyl ketone peroxide) which is a hardener.

\subsection{Sample Preparation}

In this study, sonication was performed in a glass beaker using a high intensity ultrasonic irradiation (Ti-horn, $20 \mathrm{kHz}$ Sonics Vibra Cell, Sonics Mandmaterials, Inc, USA) for 90 minutes adding 0.1-0.3 wt $\%$ CNF and $10 \mathrm{wt} \%$ styrene to polyester resin. The addition of styrene at this stage eases fabrication of composite panels using the VARTM process [24-26]. The mixing process was carried out in a pulse mode of $30 \mathrm{~s}$ on $15 \mathrm{~s}$ off at an amplitude of $50 \%$. To reduce the void formation, desiccation was carried out using a Brand Tech Vacuum system. Once the bubbles were completely removed (90 to 120 minutes) from the mixture, $0.7 \mathrm{wt} \%$ MEKP (Methyl Ethyl Ketone Peroxide) catalyst was mixed using a high-speed mechanical stirrer for about 2-3 minutes and vacuum was again applied for about 6-8 minutes to degasify the bubbles produced during the catalyst mixing. Both conventional and nanophased E-glass/polyester-CNF composites were manufactured by the VARTM process. Vacuum was maintained until the end of cure to remove any volatiles generated during the polymerization process. The panels were cured for about 12 hours at room temperature and then thermally post cured at $110{ }^{\circ} \mathrm{C}$ for 3 hours in a Lindberg/blue mechanical convection oven [27]. The overall sample fabrication procedure is presented in Fig. 1. The fiber volume fraction for the nanophased GRPCSs fabricated by the VARTM process was found

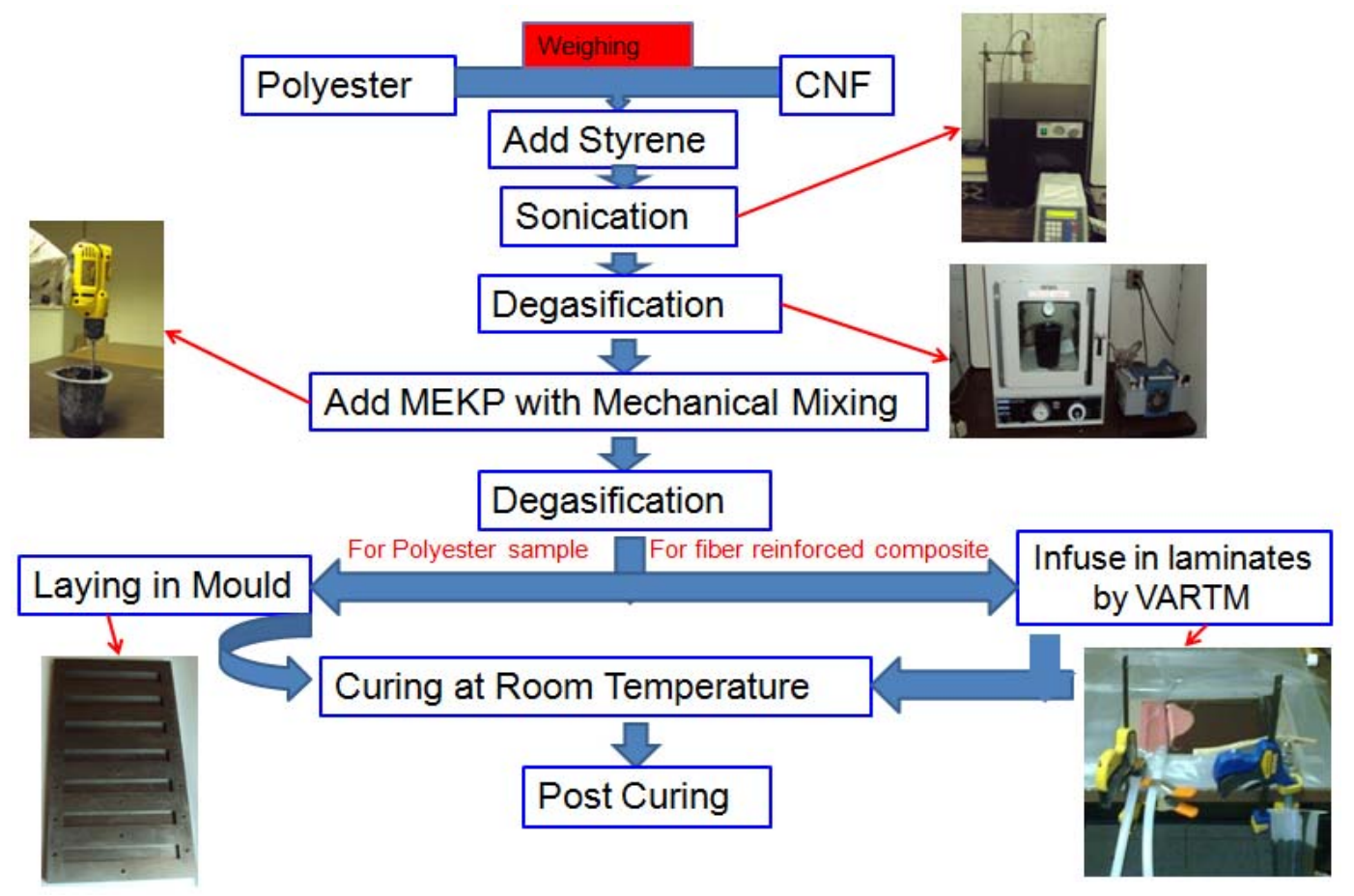

Fig. 1 Flow chart of sample fabrication. 
to be $\sim 56 \%$. The void content was measured by acid digestion test and was found to be $3.5[3,12]$.

\subsection{Scanning Electron Microscopy (SEM)}

SEM studies were carried out to examine change in the microstructure due to addition of CNFs using JEOL JSM 5800. Samples were positioned on a sample holder with a silver paint and coated with gold to prevent charge build-up.

\subsection{Quasi-Static Compression Test}

In order to investigate quasi-static compression response, samples were tested in thickness direction using servo-hydraulically controlled MTS (Material testing system) machine according to the ASTM D 695-10 standard. The test was carried out at the displacement control mode with the crosshead speed of $1.27 \mathrm{~mm} / \mathrm{min}$.

\subsection{High Strain Rate Test}

For high strain rate testing, a modified SHPB was used in this study. A typical setup of modified SHPB is shown schematically in Fig. 2. The setup consisted of a striker, incident, and transmission bars, and an incident tube (19 mm inner diameter) made of 1045 maraging steel. The length of the striker bar was 22.86 $\mathrm{cm}$ while those of incident and transmission bars were $1.524 \mathrm{~m}$ each. The incident tube was $38.1 \mathrm{~cm}$ long and had outer diameter of $26.87 \mathrm{~mm}$. Details of the setup and stress reversal technique are discussed by Hosur et al. [28]. During high strain rate loading, the sample was sandwiched between the incident bar and transmission bar. Petroleum jelly was applied at surfaces of the sample in contact with bars to reduce effect of friction. Strain gage transducers mounted on incident and transmission bars at a distance of $76.2 \mathrm{~cm}$ (30 in.) from the initial sample location were used as signal monitors.

Transient strain history was recorded from strain gages mounted on the incident and transmission bars. Two gages were mounted diametrically opposite to each other on each bar to eliminate recording of any bending strain. Data were acquired using a high-speed data acquisition card with Gagescope V3.42 software at a sampling rate of $2 \mathrm{MHz}$. The stress-strain relationship was developed based on one dimensional

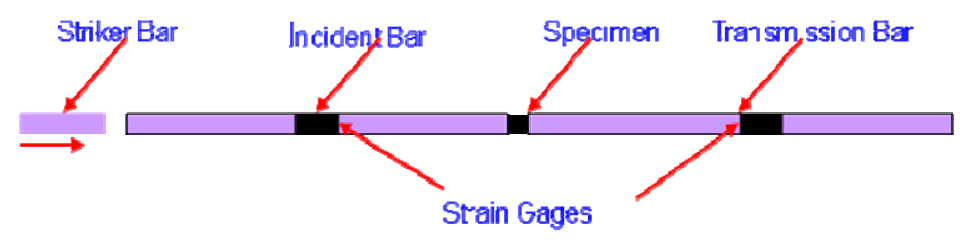

\section{Compression Split Hopkinson Pressure Bar- BarISpecimen Interface}

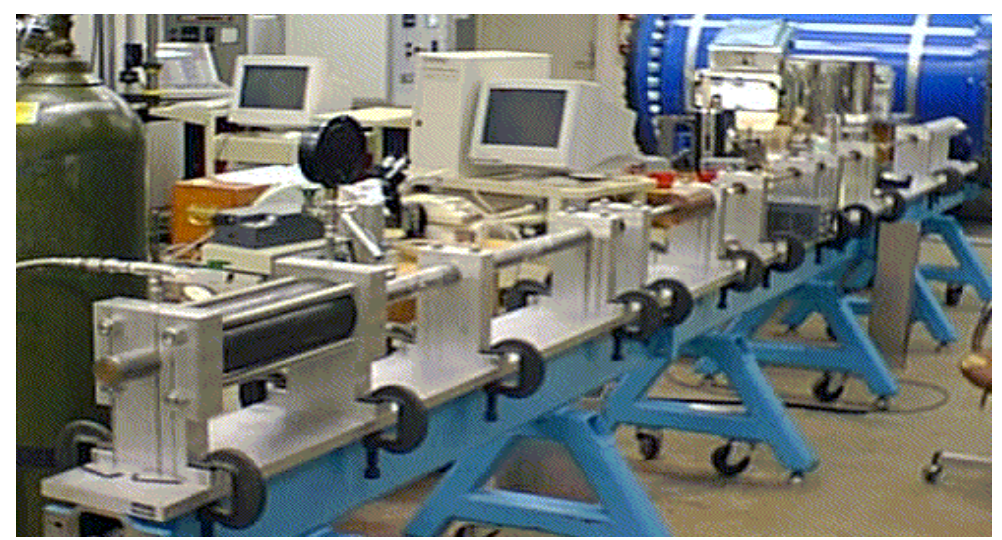

Fig. 2 Schematic of compression split Hopkinson pressure bar setup. 
elastic bar-wave theory for a pulse propagating in a uniform bar which was initially unstrained and at rest before pulse arrives. For this data analysis, VuSigno software was used.

\subsection{Optical Microscopy}

An OM was used to investigate the failure mode and crack propagation of the fractured samples. The fractured surfaces were exposed to the optical microscope using polarized light. The optical microscopy was performed using Olympus SZX16 which provided a large zoom ratio of $16.4: 1$. With this zoom ratio combined with the most comprehensive range of par focal objectives $(0.5 \mathrm{X}, 1.0 \mathrm{X}, 1.6 \mathrm{X}$ and $2.0 \mathrm{X})$, the SZX16 can be used to take micrograph from a macro-level to a micro-level allowing visualization of whole organism down to fine microscopic structures.

\section{Results and Discussion}

\subsection{SEM Analysis}

SEM was used to investigate the dispersion of CNF in the polyester. Concentrated nitric acid was added on the cleavage surfaces of the $2 \%$ polyester resin to partly unveil the CNF formerly covered by the polyester. The SEM micrograph of acid-etched surfaces revealed excellent dispersion of CNF throughout the resin (Fig. 3a). It is also observed that the interfacial bonding between the CNF and matrix is very compact which would allow CNF to be anchored in the embedding matrix. The well-separated and uniformly-embedded CNFs are likely to interlock and entangle with the polymer chains in the matrix [29]. Figs. $3 b$ and $3 c$ show the woven glass reinforced polyester laminates incorporated with $0.2 \mathrm{wt} \% \mathrm{CNFs}$. It was found that the resin was distributed uniformly over the fabric and the interfacial bonding between the matrix and fiber was very good. Proper resin flow and impregnation of glass fibers were observed in the SEM micrographs. Clear resin matrix adhesion is present in these micrographs and glass fibers are observed to be embedded within the matrix. Good matrix-fiber wetting was achieved and the resin is also visible in between glass fiber filaments. It appears that better interfacial bonding between the nanophased polymer matrix and glass fiber is present due to the presence of CNF [30].

\subsection{Quasi-Static Compression Responses}

Quasi-static tests were performed on the neat and 0.1-0.3 wt $\%$ CNF-filled glass fiber reinforced polyester composites to evaluate their compression stiffness and strength. Five samples were tested for each condition and the average properties were obtained from these tests. Their typical quasi-static (low strain rate, $10^{-3} \mathrm{~s}^{-1}$ ) stress-strain behaviors are shown in Fig. 4. The highest value of stress is identified as the peak stress or maximum stress and the

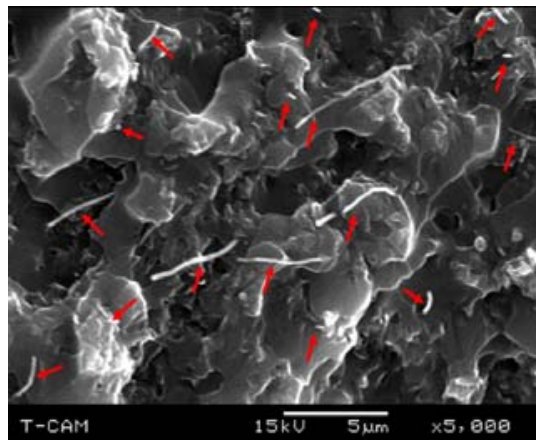

(a)

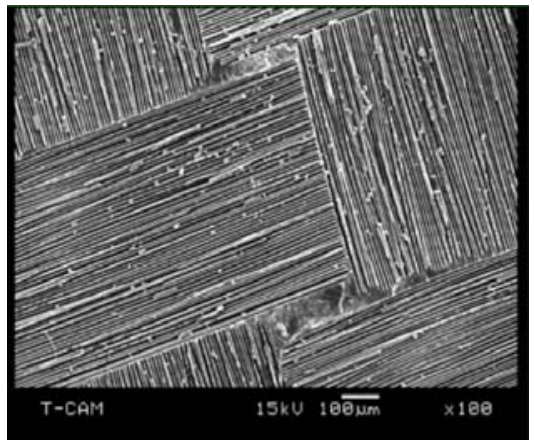

(b)

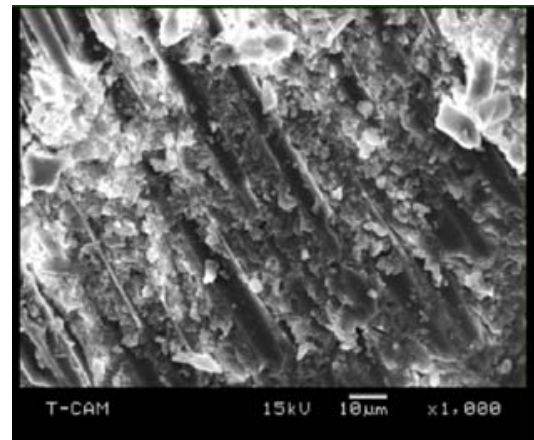

(c)

Fig. 3 SEM micrographs of (a) 0.2 wt \% CNF-loaded acid-etched polyester and (b, c) 0.2 wt. \% CNF-loaded GRPC laminates at $100 x$ and $1,000 x$, respectively. 


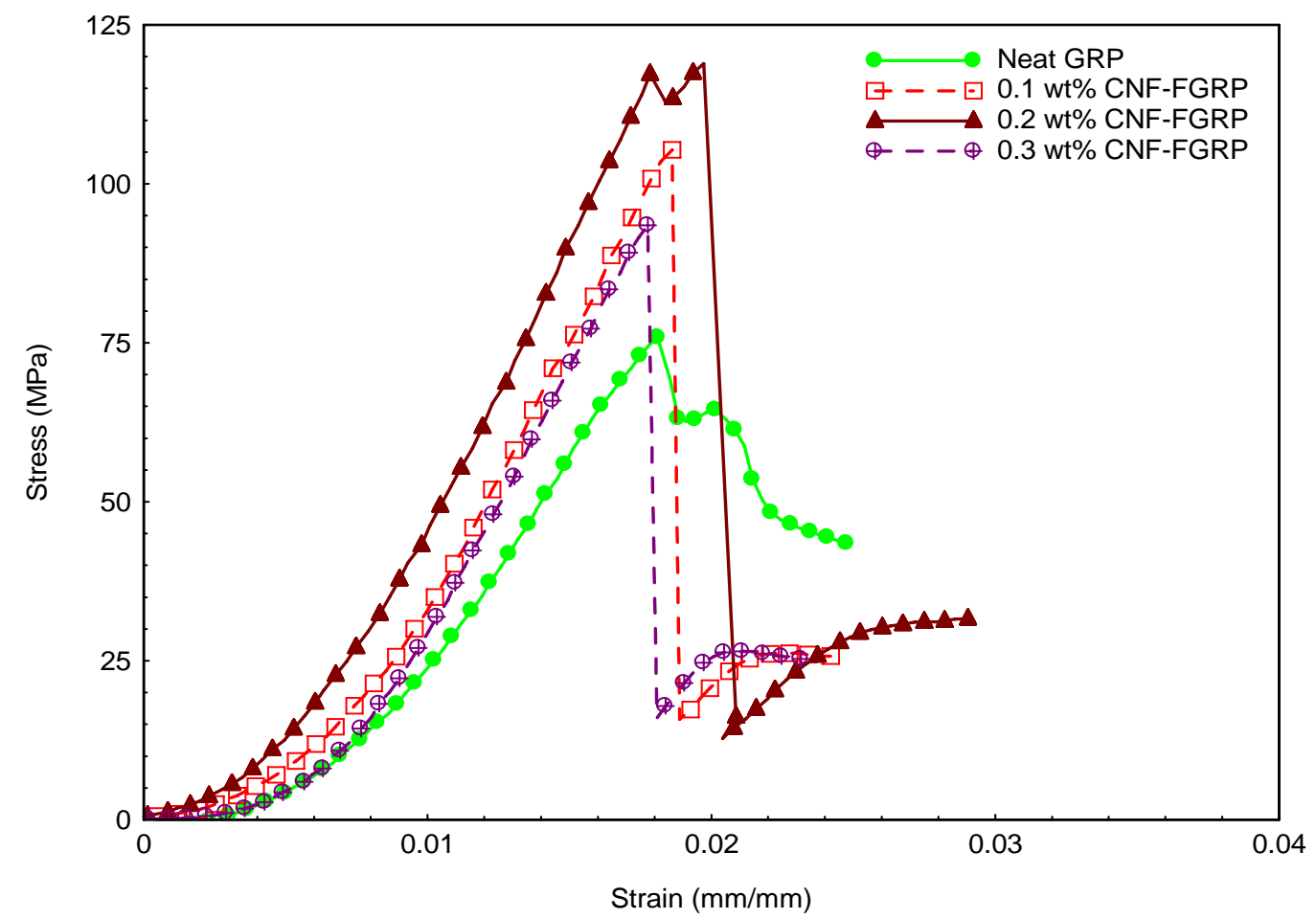

Fig. 4 Stress-strain curves of conventional and CNF-loaded GRPC.

Table 1 Quasi-static (strain rate $10^{-3} \mathrm{~s}^{-1}$ ) results of conventional and CNF-loaded GRPC.

\begin{tabular}{lllll}
\hline Composite name & Max. stress (MPa) & \% Improvement & Modulus (GPA) & \% Improvement \\
\hline Neat GRP & $80.72 \pm 6.27$ & - & $3.78 \pm 0.25$ & - \\
$0.1 \mathrm{wt} \%$ CNF-FGRP & $106.98 \pm 1.65$ & 32.50 & $5.52 \pm 0.48$ & 46.03 \\
$0.2 \mathrm{wt} \%$ CNF-FGRP & $115.71 \pm 3.25$ & 43.35 & $6.05 \pm 0.27$ & 60.05 \\
$0.3 \mathrm{wt} \%$ CNF-FGRP & $95.4 \pm 2.75$ & 18.19 & $5.14 \pm 0.44$ & 35.98 \\
\hline
\end{tabular}

corresponding strain value is hereafter mentioned as the strain at maximum stress. The modulus is determined from the slope of the linear portion of the stress vs. strain curve.

From the stress-strain curves, it was found that the incorporation of CNF enhanced the stress and modulus of the E-glass/polyester composite. The 0.2 wt $\%$ CNF-loaded laminates showed the best improvement in stress and modulus. CNFs act as resistance to crack propagation. There was a slight improvement in the strain at maximum stress due to the addition of CNF. In all cases, soon after reaching maximum stress, the samples were failed. However, brittle failure was observed in each type of laminate sample and no obvious yield point was found. The 0.2 $\mathrm{wt} \%$ CNF- loaded GRPC showed the maximum enhancement in the compressive strength and modulus by about $43 \%$ and $60 \%$, respectively, compared to conventional GRPC samples. This enhancement was also consistent with the investigation of Ma et al. [31] on the polyester/carbon nanofiber composites. Compressive failure in polymeric fiber composites occurs by yielding which results in the development and spread of kinks [32]. The CNF might act as a barrier for kinks spread, thus ensuring the enhanced compressive strength. The summarized quasi-static (low strain rate) compression results of neat GRP and CNF-Filled GRP (FGRP) composites are given in Table 1.

\subsection{Dynamic Compression Responses}

Dynamic high strain rate compression responses were performed on conventional and CNF-loaded glass/polyester laminates at three different strain rates 
of 550,700 , and $800 \mathrm{~s}^{-1}$. Data acquisition was triggered when the initial compressive pulse reached the location of the strain gage on the incident bar. The strain rate versus time and stress versus time data were stored in separate files. To plot the dynamic stress-strain curve, it is important to synchronize the two pulses. The starting time for this was when the transmitted pulse started deviating from zero and the ending time was determined when the transmitted pulse flattens out. The portion of the reflected pulse was chosen at corresponding time range and integrated to get the strain versus time data. Strain versus time and stress versus time data were superimposed to obtain the dynamic stress-strain curve.

To determine stiffness (slope of stress-strain curve), the linear portion of the curve was zoomed using the Easy Plot graphic software. The zoomed-in portion was then fitted with a linear curve, the slope of which gave the stiffness of the sample. Figs. 5 and 6 illustrate strain rate effects on dynamic stress-strain responses of conventional and $0.2 \mathrm{wt} \% \mathrm{CNF}$-loaded nanophased glass/polyester composites. Maximum stresses found in conventional GRPC were 91, 103, and $110 \mathrm{MPa}$ at strain rates of 500, 700 and $800 \mathrm{~s}^{-1}$, respectively. Moduli values were 4.87, 4.93, and 5.05 $\mathrm{GPa}$, respectively. GRPC loaded with $0.2 \mathrm{wt} \% \mathrm{CNF}$ showed maximum stresses of 126,140 , and $152 \mathrm{MPa}$ at strain rates of 500, 700 and $800 \mathrm{~s}^{-1}$, respectively, and the moduli values were 7.01, 8.35 and $10.0 \mathrm{GPa}$, respectively.

The average modulus in both conventional and nanophased composites increased with increasing strain rates. The average maximum stress also increased from quasi-static to high strain rates. Chen et al. [14] believed that this increase in stress was due to the rising strain-rates that reduced the molecular mobility of polymer chains and thus made a material stiffen. However, in high strain-rate tests, failure strain was observed to decrease by $20 \%$ which was consistent with data obtained by other researchers [33]. It was also reported that dynamic strength increases and strain-to-failure decreases with increasing strain rates [15].

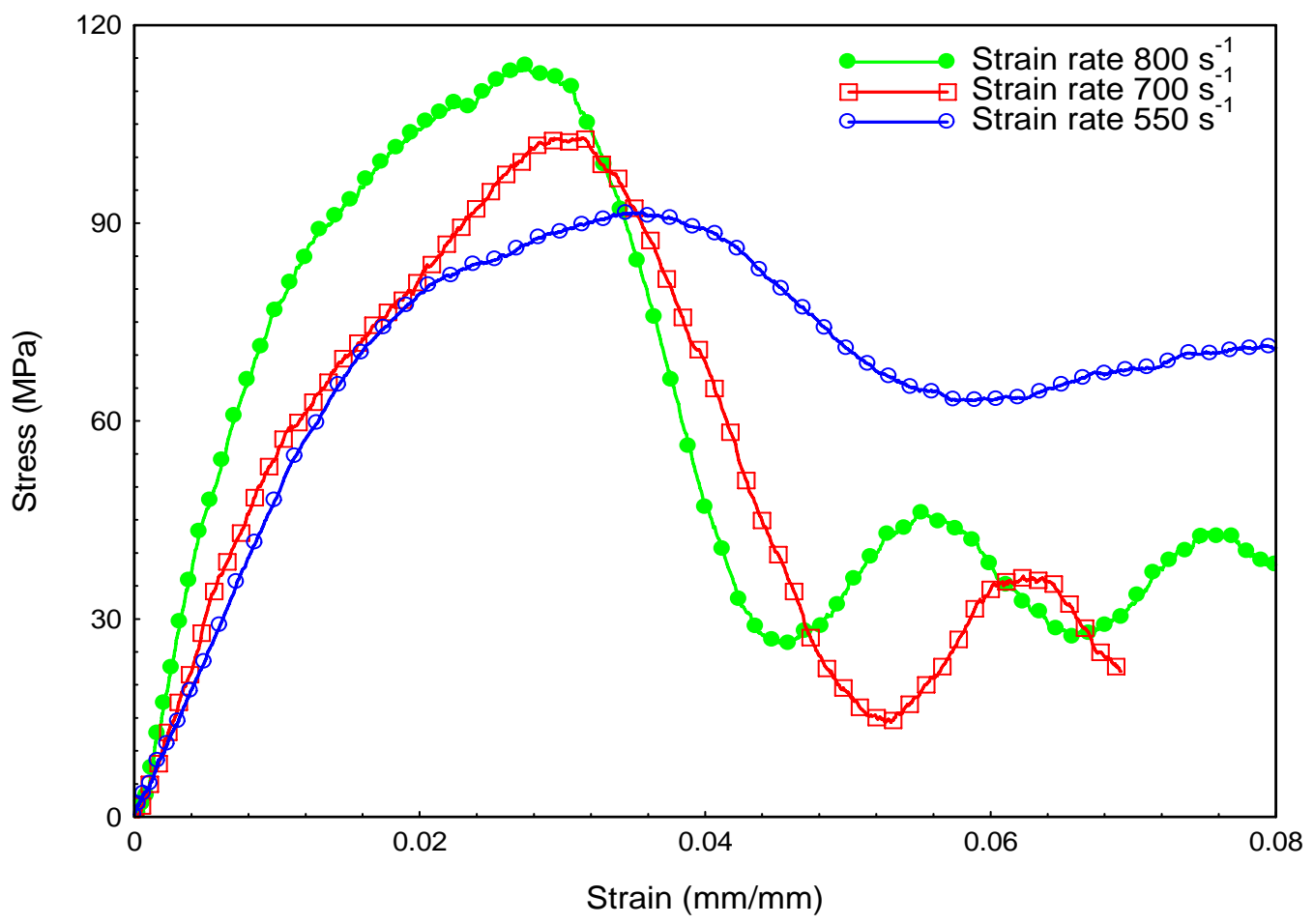

Fig. 5 Typical stress-strain curve for conventional GRPC at different strain rates. 


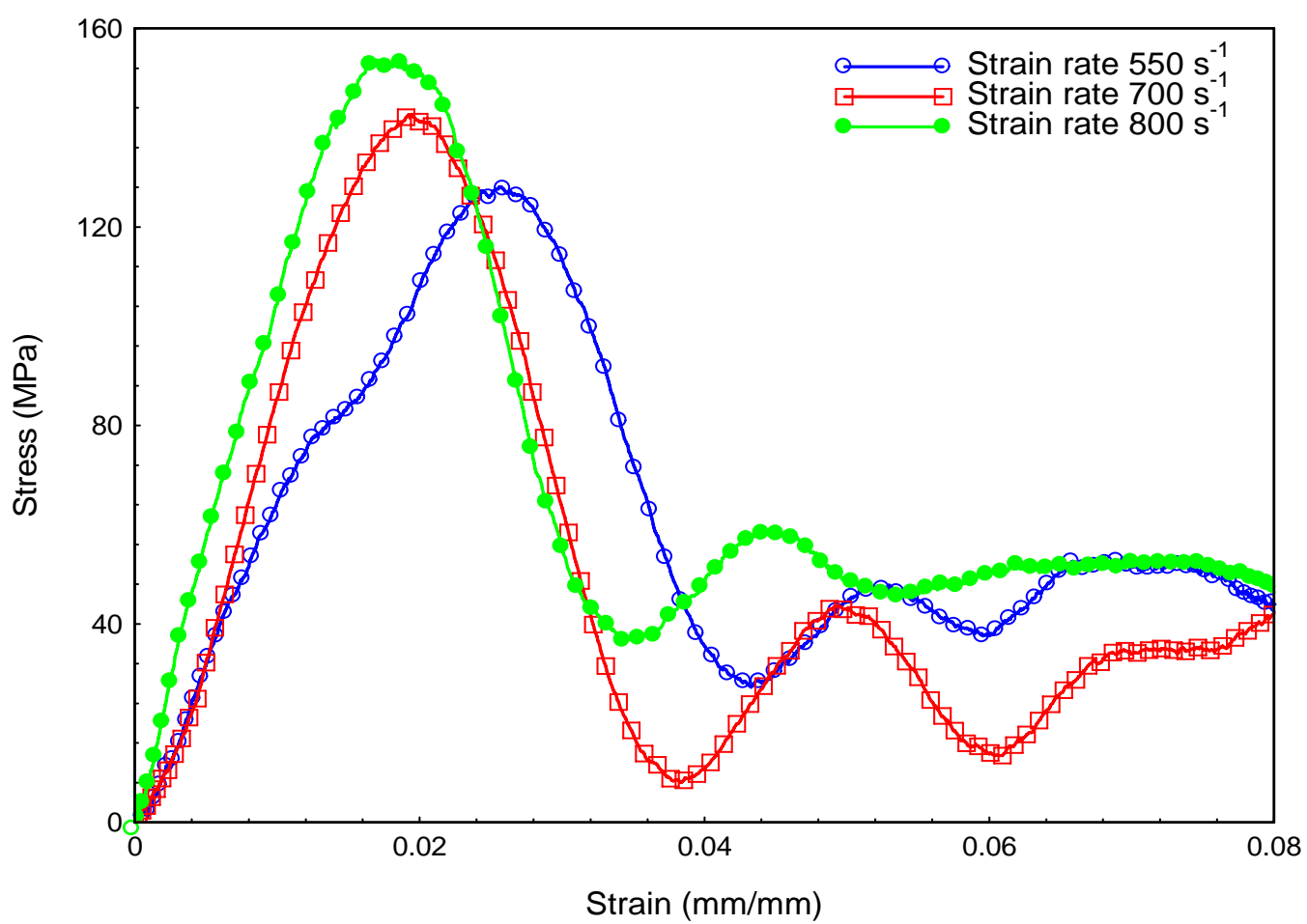

Fig. 6 Typical stress-strain curve for $0.2 \mathrm{wt} \%$ CNF-loaded GRPC at different strain rates.

Effects of CNF on the performance of composites are correlated to loading rates at different strain rates, as shown in Figs. 7-9. At $550 \mathrm{~s}^{-1}$ strain rate, all samples reached the peak load in a non-linear fashion. At higher strain rates, the strength of the CNF-filled GRPC (CNF-FGRPC) was higher compared to that of the pure composite. The addition of CNF enhances not only quasi-static properties but also dynamic properties of GRPC. However, strain at failure was slightly decreased with increasing strain rates and addition of CNF. This observation was consistent with the work of Yao et al. [34]. Data obtained from dynamic tests of neat GRPC and CNF-filled GRPC (CNF-FGRP) are shown in Table 2. Table 2 provided maximum stress, modulus, and average values with standard deviations.

\subsection{Comparison of Compressive Response at Different Strain Rates}

Fig. 10 shows peak stress vs. CNF content (wt\%) at strain rates of $10^{-3}, 550,700$, and $800 \mathrm{~s}^{-1}$. The data reveal that the $0.2 \mathrm{wt} \% \mathrm{CNF}$-filled GRPC laminates exhibited best results. It can be further seen that for conventional, $0.2 \mathrm{wt} \%$ and $0.3 \mathrm{wt} \%$ CNF-filled GRPC samples peak stresses increase with increasing strain rates. At lower strain rates, the cracks tend to propagate through the preferential paths in matrix avoiding most of the glass fiber and CNFs. At higher strain rates, the cracks may not find enough time to follow a preferential path, encountering glass fiber and CNFs which are stronger than the matrix $[35,36]$.

In the case of $0.1 \mathrm{wt} \%$ CNF-loaded GRPC, peak stress data show an anomaly. Here, the peak stress at quasi-static test came out higher than that of at $550 \mathrm{~s}^{-1}$ and $700 \mathrm{~s}^{-1}$ strain rates. All five test samples revealed this trend. The reason for this anomaly is not clear at this time.

Fig. 11 shows modulus vs. CNF content (wt\%) for $10^{-3}, 550,700$, and $800 \mathrm{~s}^{-1}$ strain rates. The data revealed that the $0.2 \mathrm{wt} \%$ CNF-filled GRPC laminates exhibited best results. Conventional as well as all CNF-infused GRPC samples (except $0.1 \quad$ wt $\%$ samples) exhibited higher value of modulus with increasing strain rates. The modulus at quasi-static test 
came out slightly higher than that at $550 \mathrm{~s}^{-1}$ strain rate. This anomaly was expected because the modulus was calculated from the same stress-strain curves as in peak stress calculations.

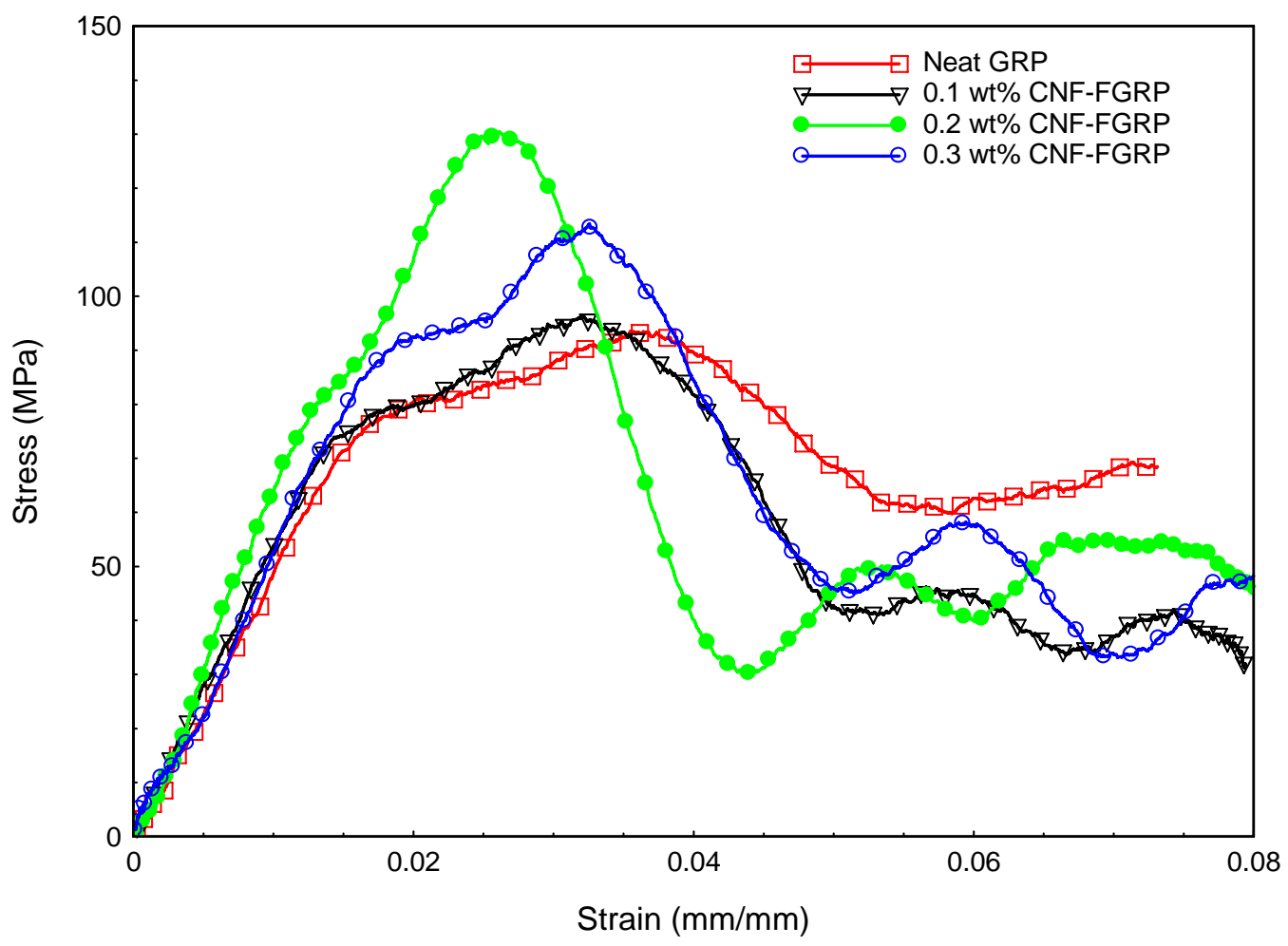

Fig. 7 Stress-strain response of conventional and CNF-loaded GRPC at strain rate $550 \mathrm{~s}^{-1}$.

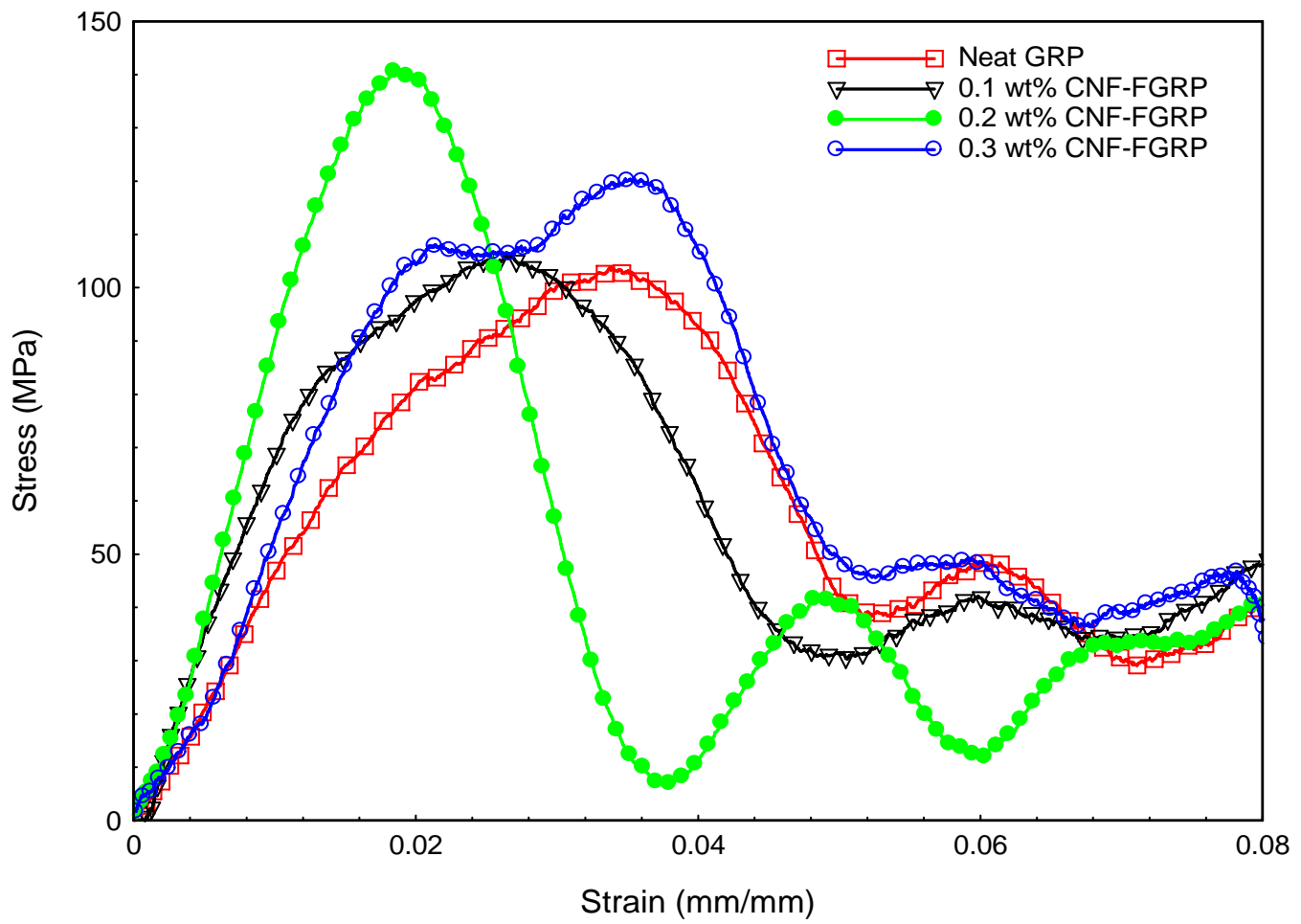

Fig. 8 Stress-strain response of conventional and CNF-loaded GRPC at strain rate $700 \mathrm{~s}^{-1}$. 


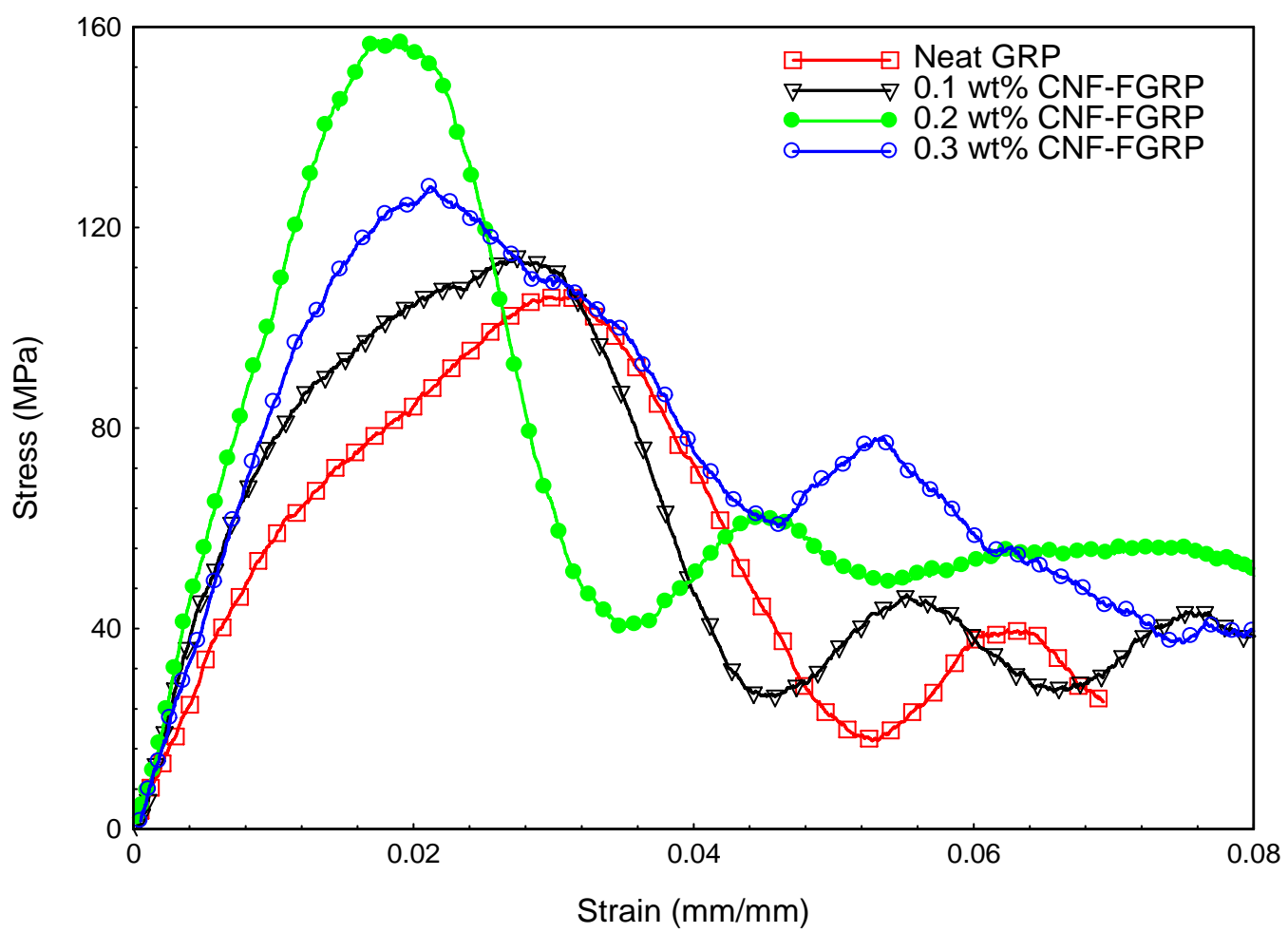

Fig. 9 Stress-strain responses of conventional and CNF-loaded GRPC at strain rate $800 \mathrm{~s}^{-1}$.

Table 2 Compressive properties of conventional and nanophased GRPC at different strain rates.

\begin{tabular}{llll}
\hline Strain Rate, $\mathbf{S}^{\mathbf{1}}$ & Composites & Max. stress, MPa & Modulus, GPa \\
\hline \multirow{3}{*}{$\mathbf{5 5 0}$} & Conventional GRP & $92 \pm 4.1$ & $4.87 \pm 0.25$ \\
& $0.1 \mathrm{wt} \%$ CNF-FGRP & $96 \pm 3.7$ & $5.26 \pm 0.28$ \\
& $0.2 \mathrm{wt} \%$ CNF-FGRP & $126 \pm 3.1$ & $7.01 \pm 0.31$ \\
& $0.3 \mathrm{wt} \%$ CNF-FGRP & $112 \pm 4.2$ & $5.71 \pm 0.42$ \\
\hline \multirow{3}{*00}{} & Conventional GRP & $103 \pm 4.8$ & $4.93 \pm 0.30$ \\
& $0.1 \mathrm{wt} \%$ CNF-FGRP & $105 \pm 4.1$ & $6.32 \pm 0.41$ \\
& $0.2 \mathrm{wt} \%$ CNF-FGRP & $140 \pm 3.8$ & $8.35 \pm 0.33$ \\
& $0.3 \mathrm{wt} \%$ CNF-FGRP & $121 \pm 4.6$ & $6.05 \pm 0.43$ \\
$\mathbf{8 0 0}$ & Conventional GRP & $110 \pm 4.9$ & $5.05 \pm 0.33$ \\
& $0.1 \mathrm{wt} \%$ CNF-FGRP & $115 \pm 4.2$ & $6.85 \pm 0.40$ \\
& $0.2 \mathrm{wt} \%$ CNF-FGRP & $152 \pm 3.7$ & $9.91 \pm 0.34$ \\
\hline
\end{tabular}

\subsection{Fracture Morphology Analysis}

The fracture behavior of tested samples at the quasi-static strain rate of $10^{-3} \mathrm{~s}^{-1}$ is shown in optical micrographs in Fig. 12. At first, some cracks were initiated in the samples followed by the kink band formation and crack propagation upon reaching the maximum peak stress, catastrophic load drop was observed and samples failed in the direction of compression loading (Fig. 12). It is evident from these micrographs that matrix cracking, kinking, and fiber breakage dominated the failure modes of 0.1-0.2 wt\% CNF-loaded nanophased composites whereas matrix cracking and delamination were mostly observed in the $0.3 \mathrm{wt} \% \quad \mathrm{CNF}$-infused and conventional composites. It appears that the sonication process was unable to break the agglomerations of the $0.3 \mathrm{wt} \%$ CNF-loaded composites completely. The modulus, a low deformation property, was not affected by the 
high stress concentrations caused by the agglomerated particles. However, the strength was reduced by initiating early failure in the matrix [37]. This explains the decrease in compressive strength observed in the $0.3 \%$ CNF-loaded glass fiber reinforced composite. It has been reported that even at low concentration of

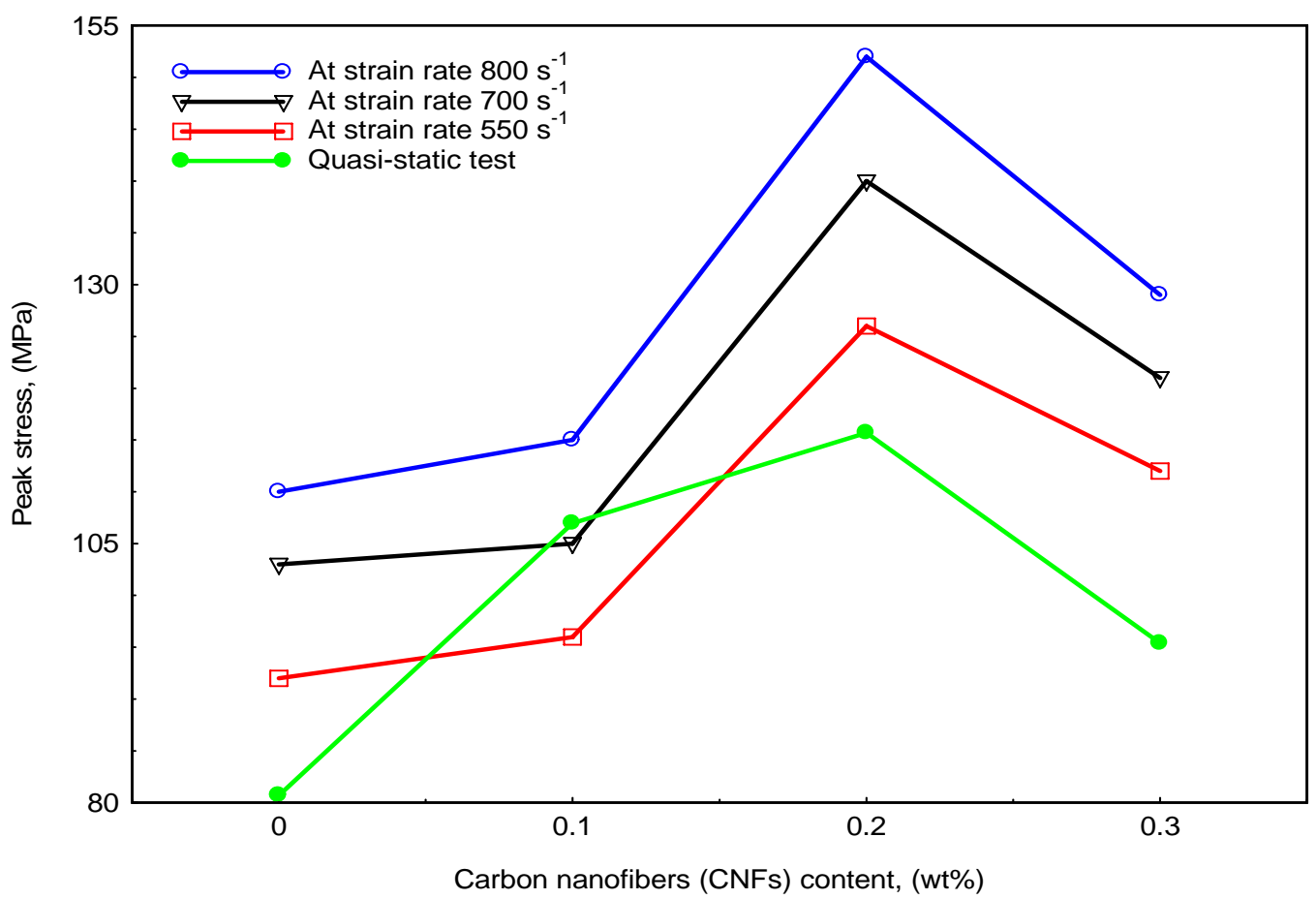

Fig. 10 Peak stress vs. CNF contents at different strain rates.

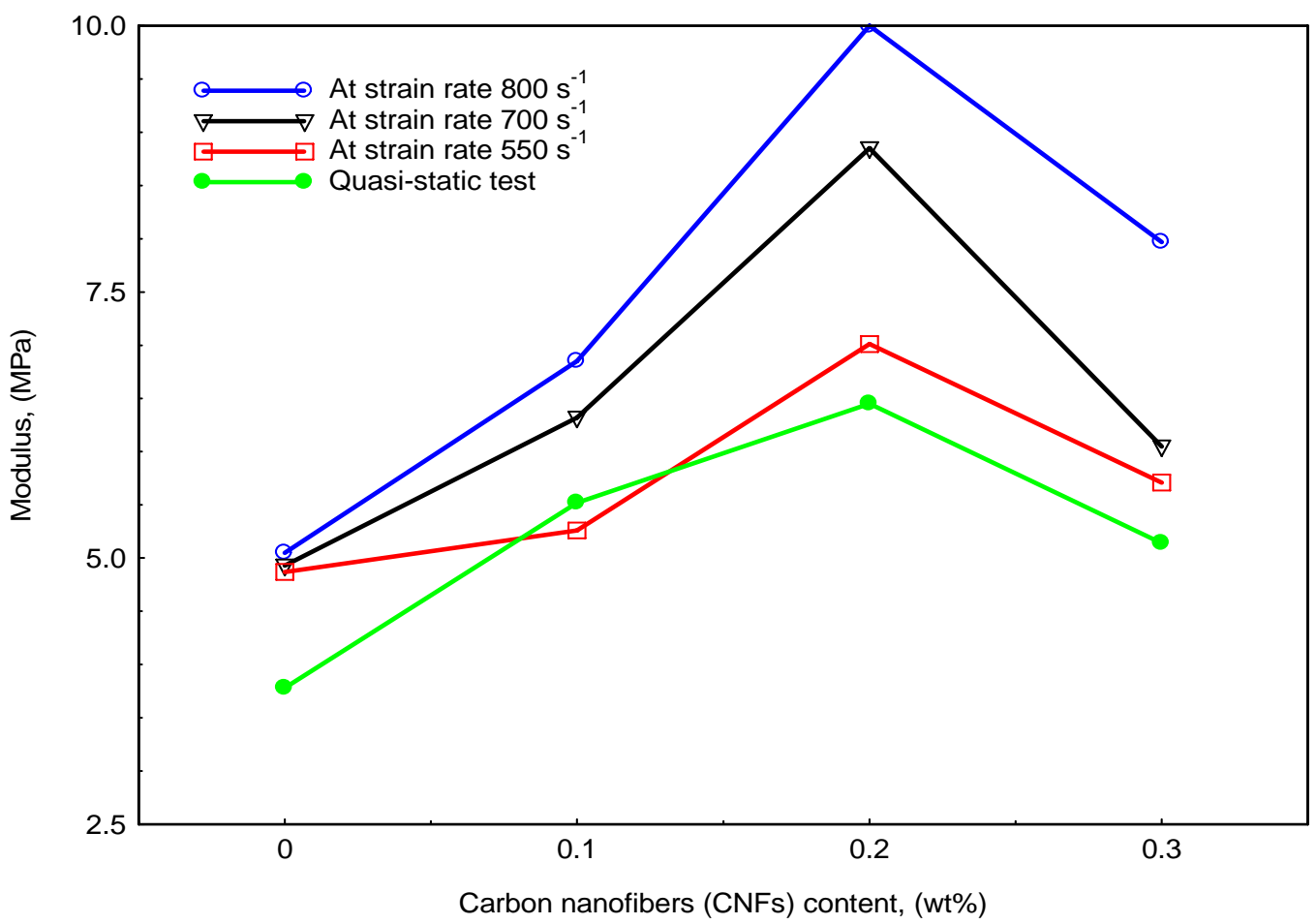

Fig. 11 Modulus vs. CNF contents at different strain rates. 


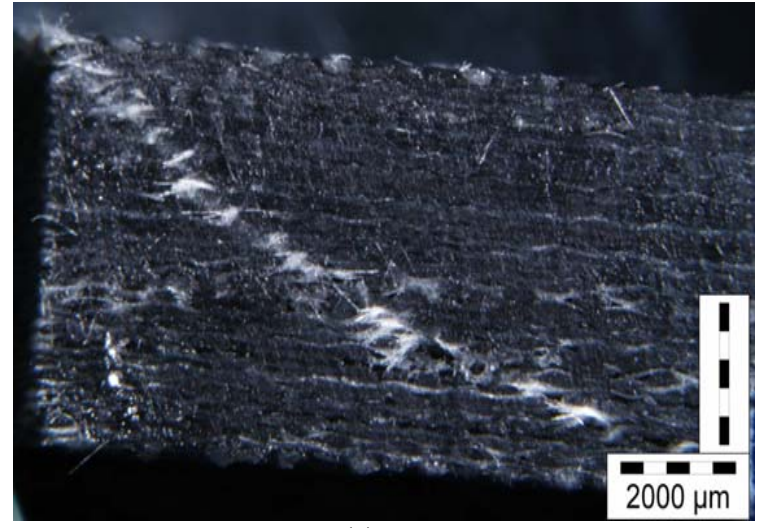

(a)

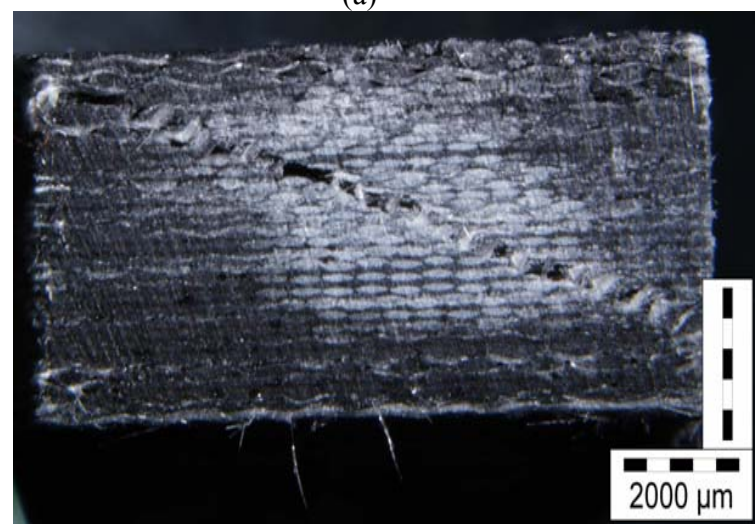

(c)

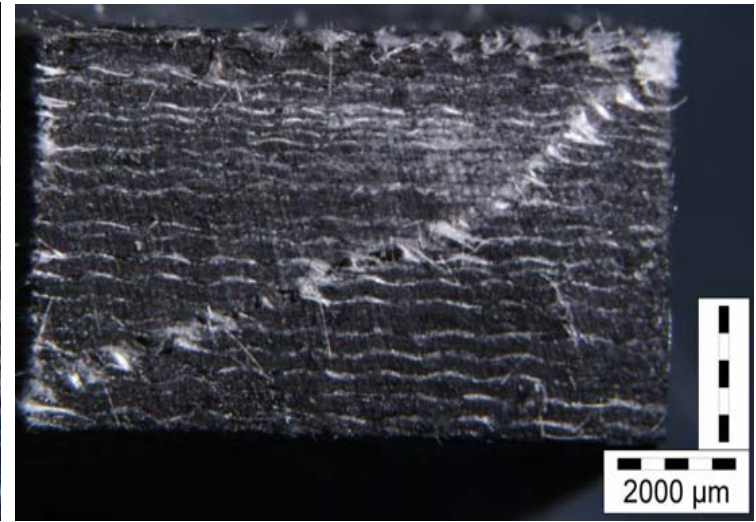

(b)

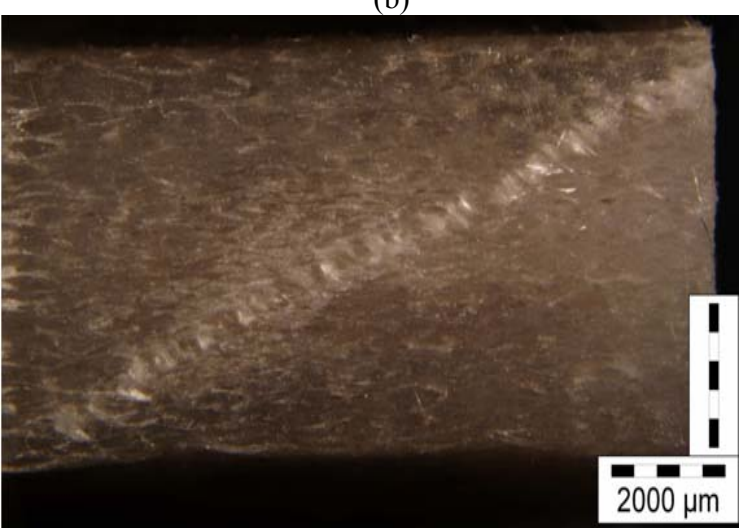

(d)

Fig. 12 Fracture Morphology of GRPC at Low Strain Rate (Quasi-Static, $10^{-3} \mathrm{~s}^{-1}$ ) Tests: (a) $0.1 \mathrm{wt} \%$ CNF-Loaded GRPC, (b) 0.2 wt \% CNF-Loaded GRPC, (c) 0.3 wt \% CNF-Loaded GRPC and (d) Conventional GRPC.

nanoparticles the fracture energy of polyester nanocomposites could be doubled and prevent large scale fragmentation of polyester matrix [38]. This behavior is clearly seen from OM micrographs.

For better understanding, fracture morphology of samples was studied using higher magnification SEM micrographs. The SEM micrographs of the fractured surfaces of the conventional and $0.2 \mathrm{wt} \% \mathrm{CNF}$-loaded GRPC are illustrated in Fig. 13. For the conventional composite shown in Fig. 13a, the surface of the fiber was clean, and no matrix adhered to the fiber. The fracture surface of the matrix was flat, and some cracks were seen in the matrix side near the fiber-matrix interface. The resin appears not to protrude from the surface of fibers. These results indicate that the interfacial bonding between the fiber and matrix was weak. The fracture surfaces of the nanophased composite (Fig. 13b) show that the surface of the matrix was rougher than that of the neat composite. CNFs were observed to be randomly but uniformly distributed in the matrix. The resin appears to cling to fibers well. The strengthened matrix held the glass fabrics together. The protrusion of the resin from the surface of the fibers accounts for the increase in fracture toughness of the samples. Moreover, the resin appears to be sticking to the fiber surface giving rise to a significant plastic deformation [39]. The plastic deformation enhances mechanical properties significantly in nanophased composites (Fig. 4).

The fracture behavior of conventional and $0.2 \mathrm{wt} \%$ CNF-loaded GRPC samples tested at a strain rate of $550 \mathrm{~s}^{-1}$ and $700 \mathrm{~s}^{-1}$ are shown in Figs. 14 and 15, respectively. At first, numerous cracks were initiated in the samples followed by kink band formation and crack propagation. Neat samples at $550 \mathrm{~s}^{-1}$ failed due to mostly delamination whereas $0.2 \mathrm{wt} \%$ CNF-loaded samples failed due to kink band formations which lead to crack propagation and fracture of sample. GRPC 


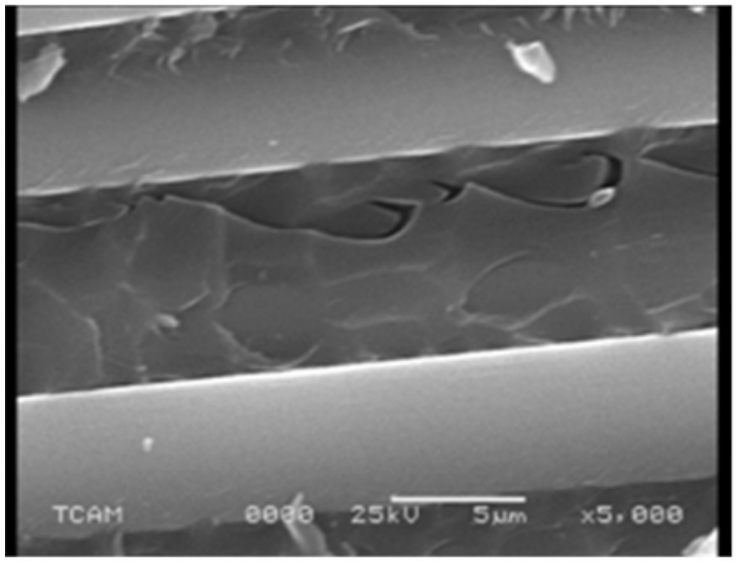

(a)

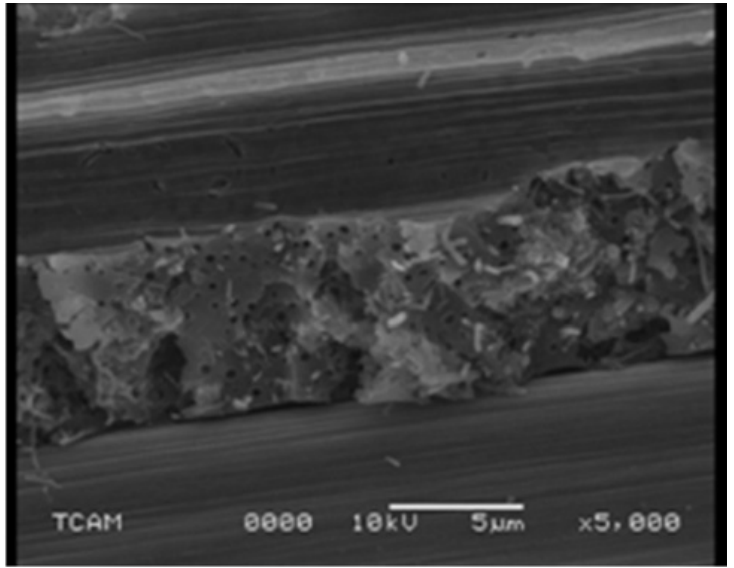

(b)

Fig. 13 Fracture of (a) Conventional and (b) $0.2 \mathrm{wt} \%$ CNF-loaded GRPC at Low Strain Rate (Quasi-Static, $10^{-3} \mathrm{~s}^{-1}$ ) Tests.

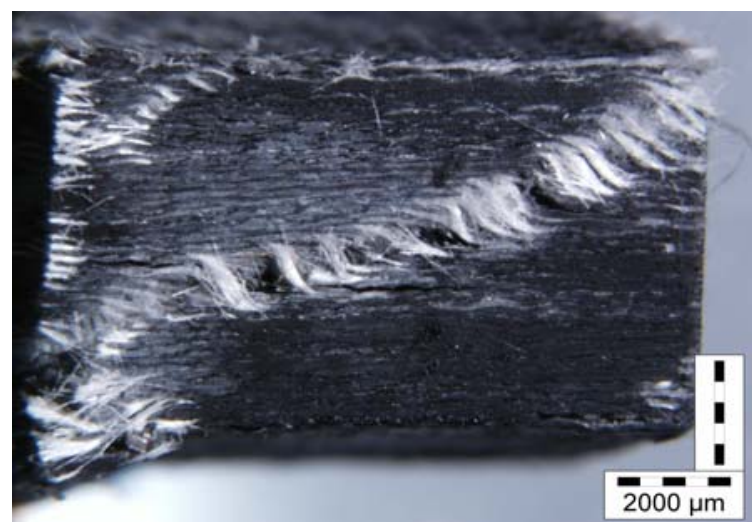

(a)

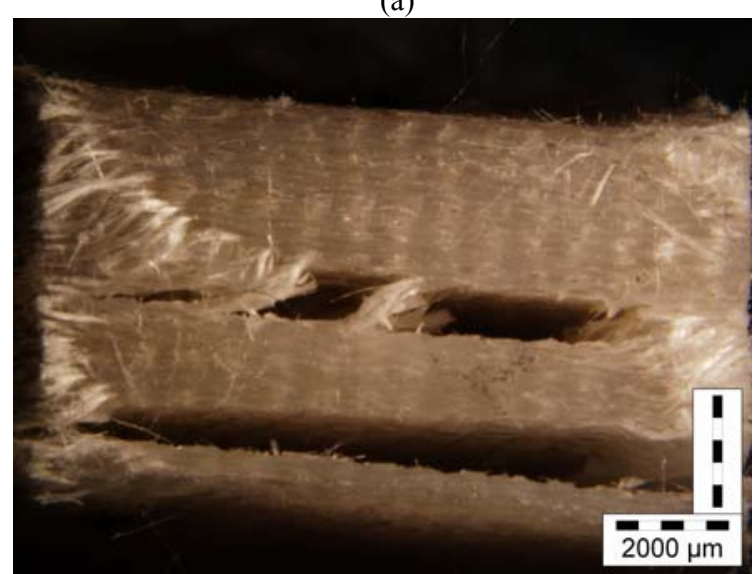

(c)

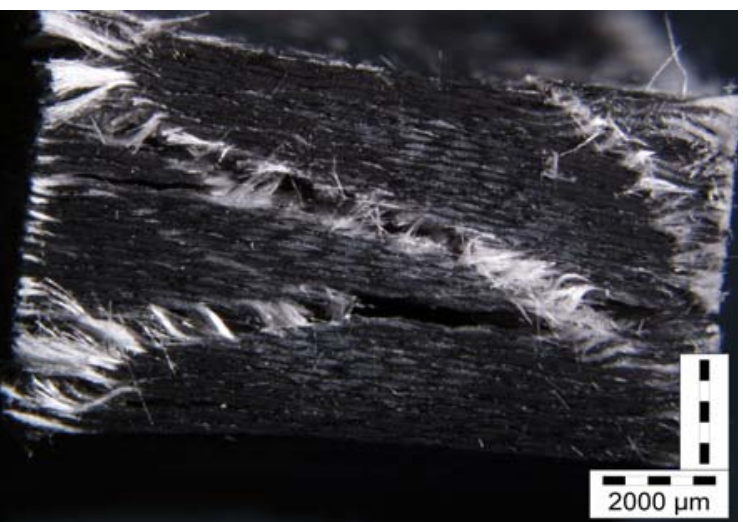

(b)

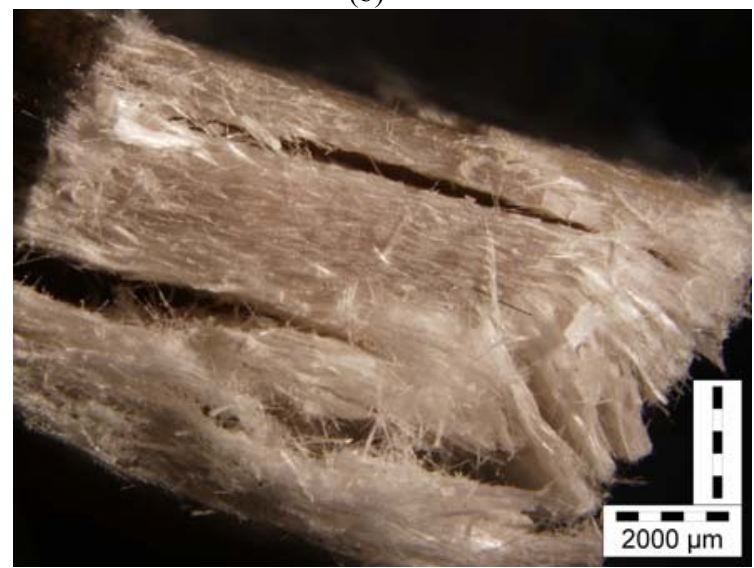

(d)

Fig. 14 Fracture behavior of GRPC at a strain rate of $550 \mathrm{~s}^{-1}$ : (a, b) $0.2 \mathrm{wt} \%$ CNF-loaded GRPC, (c, d) conventional GRPC.

loaded with $0.2 \mathrm{wt} \% \mathrm{CNF}$ samples showed less delamination and minimal crushing in comparison to neat GRPC samples. However, with increasing strain rate, no difference was observed in the failure behavior of neat and nanophased composites.

At $700 \mathrm{~s}^{-1}$ strain rate, nanophased samples showed less crushing than neat and also kinking was dominated in nanophased samples as shown in optical micrographs in Fig. 15. All samples were crushed completely at strain rate of $800 \mathrm{~s}^{-1}$. These results obviously reveal the impact of adding CNF in polyester matrix that resulted in overall enhancement 


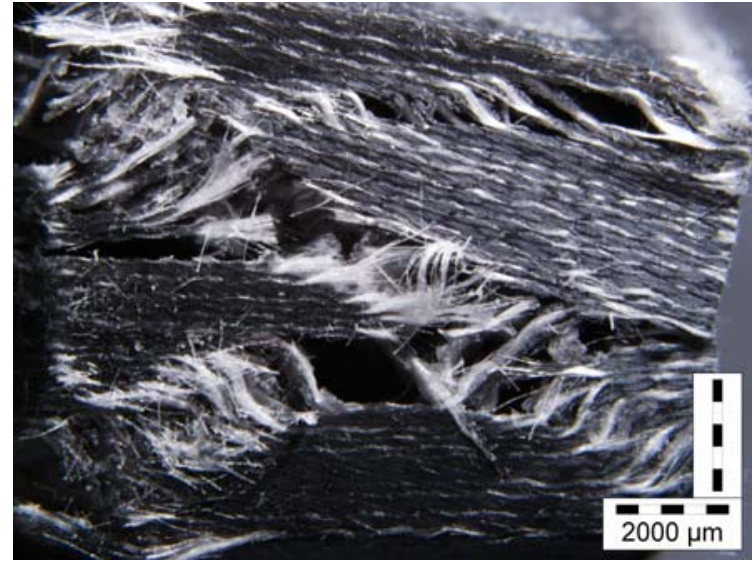

(a)

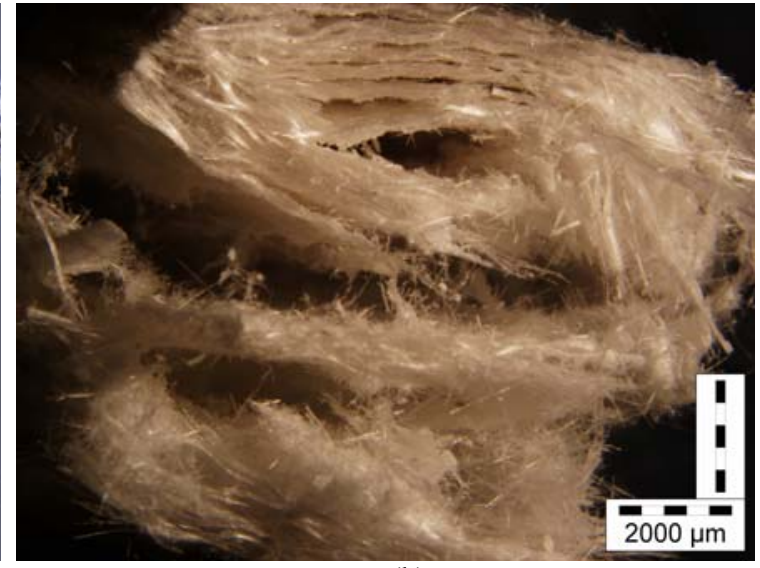

(b)

Fig. 15 Fracture behavior of GRPC at a strain rate of $700 \mathrm{~s}^{-1}$ : (a) $0.2 \mathrm{wt} \%$ CNF-loaded GRPC, (b) conventional GRPC.

in properties of glass reinforced polyester composites.

\section{Conclusions}

Carbon nanofibers (CNF) were used as nanoparticle fillers in woven glass fiber-reinforced polyester composites fabricated by VARTM process. CNF infusion even at quite low concentrations enhanced mechanical properties of composites. From SEM micrographs, better dispersion of CNF was observed in the $0.2 \mathrm{wt} \% \mathrm{CNF}$-loaded polyester resin sonicated for 90 minute. GRPC laminates infused with $0.2 \%$ CNF showed maximum enhancement in compressive strength and modulus by about $43 \%$ and $60 \%$, respectively, over conventional GRPC samples. Carbon nanofibers act as a barrier for kinks spread, thus ensuring enhanced compressive strength.

When static and dynamic compression responses were compared, it was found that peak stresses for conventional, $0.2 \mathrm{wt} \%$, and $0.3 \mathrm{wt} \%$ CNF-infused samples at high strain rates $\left(550,700\right.$, and $\left.800 \mathrm{~s}^{-1}\right)$ tests are higher compared to that at low strain rate (quasi-static, $10^{-3} \mathrm{~s}^{-1}$ ) tests. All CNF-infused GRPC at low strain rate, $10^{-3} \mathrm{~s}^{-1}$ to high strain rate, $800 \mathrm{~s}^{-1}$ exhibited larger modulus than the unfilled GRPC. This phenomenon was more pronounced at $0.2 \mathrm{wt} \%$ and $0.3 \mathrm{wt} \%$ CNF-loaded GRPC composites. Lesser damage area and better interfacial bonding in nanophased samples were evident from optical and SEM micrographs, respectively. Enhanced interfacial bonding between the fiber and matrix was also pragmatic even after failure of samples.

\section{Acknowledgements}

The authors acknowledge the financial support of NSF-RISE Grant No. HRD-0833158 to carry out this research work.

\section{References}

[1] Millerschin, E. 1999. "The Rise of Composites in the Automotive Market.” Composites Fabrication Jan.: 40-2.

[2] Hossain, M. E., Hossain, M. K., Hosur, M. V. and Jeelani, S. 2015. "Effect of Dispersion Conditions on the Thermal and Mechanical Properties of Carbon Nanofiber-Polyester Nanocomposites." Engineering Materials and Technology 137: 031005-9.

[3] Hossain, M. K., Hossain, M. E., Hosur, M. V. and Jeelani, S. 2011. "Flexural and Compression Response of Woven E-Glass/Polyester-CNF Nanophased Composites." Composites Part A: Applied Science and Manufacturing 42: 1774-82.

[4] Hossain, M. K., Hossain, M. E., Dewan, M. W., Hosur, M. V. and Jeelani, S. 2013. "Effects of Carbon Nanofiber (CNF) on Thermal and Interlaminar Shear Response of E-Glass/Polyester Composites." Composites Part B: Engineering 44: 313-20.

[5] Rajapakse, Y. D. S. 1995. "Recent Advances in Composite Research for Marine Structures." In Proceedings of the $2^{\text {nd }}$ International Conference on Sandwich Construction 3 (2): 475-86.

[6] Sandler, J., Werner, P., Shaffer, M. S. P., Demchuk, V., Altstädt, V. and Windle, A. H. 2002. "Carbon Nanofibers Reinforced Poly (ether ether ketone) Composites." Composites Part A: Applied Science and Manufacturing 
33:1033-9.

[7] Adams, W. W. and Kumar, S. 1992. "Conventional and Molecular Composites-Past, Present, and Future in Ultrastructure Processing of Advanced Materials." Uhlmann DR and Ulrich DR (Ed.). In Ultrastructure Processing of Advanced Materials 343-59: John Wiley and Sons.

[8] Chun, L., W., Ming, Q. Z., Min, Z. R. and Friedrich, K. 2002. "Tensile Performance Improvement of Low Nanoparticles Filled-Polypropylene Composites." Composites Science and Technology 62: 1327-40.

[9] Liu, W., Hoa, S., V. and Pugh, M. 2005. "Fracture Toughness and Water Uptake Of High-Performance Epoxy/Nanoclay Nanocomposites." Composites Science and Technology 65: 2364-73.

[10] Yasmin, A., Abot, J. L. and Daniel, I. M. 2003. "Processing of Clay/Epoxy Nanocomposites by Shear Mixing." Scripta Materialia 49 (1):81-6.

[11] Giannelis, E., P. 1998. "Polymer-Layered Silicate Nanocomposites: Synthesis, Properties and Applications." Applied Organometallic Chemistry 12: 675-80.

[12] Hossain, M. E., Hossain, M. K., Hosur, M. V. and Jeelani, S. 2014. "Low Velocity Impact Behavior of CNF-Filled Glass Reinforced Polyester Composites." Composite Materials 2014: 48: 879-96.

[13] Hsiao, K. and Gangireddy, S. 2008. "Investigation on the Springi Phenomenon of Carbon Nanofiber-Glass Fiber/Polyester Composites Manufactured with VARTM." Composites Part A: Applied Science and Manufacturing 39: 834-42.

[14] Chen, L. P., Yee, A. F. and Moskala, E. J. 1999. "The Molecular Basis for the Relationship between the Secondary Relaxation and Mechanical Properties of a Series of Polyester Copolymer Glasses." Macromolecules 32: 5944-55.

[15] Ochola, R. O., Marcus, K., Nurick, G. N. and Franz, T. 2004. "Mechanical Behavior of Glass and Carbon Fiber Reinforced Composites at Varying Strain Rates." Composite Structures 63: 455-67.

[16] Rio, T. G., Rodriguez, J. and Pearson, R. A. 2014. "Compressive Properties of Nanoparticle Modified Epoxy Resin at Different Strain Rates." Composites Part B: Engineering 57: 173-9.

[17] Hosur, M. V., Alexander, J., Jeelani, S., Vaidya, U. K. and Mayer, A. 2003. "High Strain Rate Compression Response of Affordable Woven Fabric Composites." Reinforced Plastics and Composites 22 (3): 271-96.

[18] Guden, M., Yildirim, U. and Hall, I. W. 2004. "Effect of Strain Rate on the Compression Behavior of a Woven Glass Fiber/SC-15 Composite." Polymer Testing 23: 719-25.
[19] Guo, Y. and Li, Y. 2007. "Quasi-Static/Dynamic Response of $\mathrm{SiO}_{2}$-Epoxy Nanocomposites." Materials Science and Engineering A 458: 330-5.

[20] Tsai, J. L. and Huang, J. C. 2006. "Strain Rate Effect on Mechanical Behaviors of Nylon 6-Clay Nanocomposites." Composite Materials 40 (10): 925-38.

[21] Evora, V. M. E. and Shukla, A. 2003. "Fabrication, Characterization, and Dynamic Behavior of Polyester/Tio 2 Nanocomposites." Materials Science and Engineering A 361: 358-66.

[22] Ingram, J., Zhou, Y., Jeelani, S., Lacy, T. and Horstemeyer, M. F. 2008. "Effect of Strain Rate on Tensile Behavior of Polypropylene and Carbon Nanofiber Filled Polypropylene." Materials Science and Engineering A 489: 99-106.

[23] Boumbimba, R. M., Wang, K., Bahlouli, N., Ahzi, S., Remond, Y. and Addiego, F. 2012. "Experimental Investigation and Micromechanical Modeling of High Strain Rate Compressive Yield Stress of a Melt Mixing Polypropylene Organoclay Nanocomposites." Mechanics of Materials 52: 58-68.

[24] Mahfuz, H., Das, D., Powell, F. and Granata, R. 2010. "Reinforcement of Syntactic Foam With $\mathrm{SiC}$ Nanoparticles." In Proceedings of the SAMPE'10 International SAMPE Symposium and Exhibition.

[25] US Composites. Chemicals \& Catalysts. Accessed June 11, 2010. http://www.uscomposites.com/solvents.html.

[26] Sakin, R., Ay, I. and Yaman, R. 2008. “An Investigation of Bending Fatigue Behavior for Glass-Fiber Reinforced Polyester Composite Materials." Materials and Design 29: 212-7.

[27] Tanoglu, M. and Seyhan, A. T. 2003. "Investigating the Effects of a Polyester Preforming Binder on the Mechanical and Ballistic Performance of E-Glass Fiber Reinforced Polyester Composites." Adhesion \& Adhesives 23: 1-8.

[28] Hosur, M. V., Alexander, J., Vaidya, U. K. and Jeelani, S. 2001. "High Strain Rate Compression Response of Carbon/Epoxy Laminates Composites." Composite Structures 52: 405-17.

[29] Li, X. F., Lau, K. T. and Yin, Y. S. 2008. "Mechanical Properties of Epoxy-Based Composites using Coiled Carbon Nanotubes." Composites Science and Technology 68: 2876-81.

[30] Green, K. J., Dean, D. R., Vaidya, U. K. and Nyairo, E. 2009. "Multiscale Fiber Reinforced Composites based on a Carbon Nanofiber/Epoxy Nanophased Polymer Matrix: Synthesis, Mechanical and Thermomechanical Behavior. Composites Part A: Applied Science and Manufacturing 40 (9): 1470-5.

[31] Ma, H., Zeng, J., Realff, M. L., Kumar, S. and Schiraldi, D. A. 2003. "Processing, Structure, And Properties of 


\section{Comparison of Quasi-Static and Dynamic Compressive Response of E-Glass/Polyester-CNF Nanocomposites}

Fibers from Polyester/Carbon Naofiber Composites." Composites Science and Technology 63: 1617-28.

[32] Kozey, V. V., Jiang, H., Mehta, V. R. and Kumar, S. 1995. "Compressive Behavior of Materials, Part II: High Performance Fibers." Materials Research 10 (4): 1044-61.

[33] Majzoobi, G. H., Saniee, F. F. and Bahrami, M. A. 2005. "Tensile Impact Apparatus for Characterization of Fibrous Composites at High Strain Rates. "Materials Processing Technology 162: 76-82.

[34] Yao, X. F., Yeh, H., Y., Zhou, D. and Zhang, Y. H. 2006. "The Structural Characterization and Properties of $\mathrm{SiO}_{2}$-Epoxy Nanocomposites." Composite Materials 40 (4): 371-81.

[35] Woldesenbete, E., Gupta, N. and Jadhav, A. 2005.
"Effects of Density and Strain Rate on Properties of Syntactic Foams." Materials Science 40 (15): 4009-17.

[36] Peter, S. and Woldesenbet, E. 2008. "Nanoclay Syntactic Foam Composites-High Strain Rate Properties." Materials Science and Engineering A 494: 179-87.

[37] Zhou, Y., Pervin, F., Jeelani, S. and Mallick, P. K. 2008. "Improvement in Mechanical Properties of Carbon Fabric-Epoxy Composite using Carbon Nanofibers." Materials Processing Technology 198 (1-3): 445-53.

[38] Jawahar, P., Gnanamoorthy, R. and Balasubramanian, M. 2006. "Tribological Behavior of Clay-Thermoset Polyester Nanocomposites.” Wear 261: 835-40.

[39] Xu, Y. and Hoa, S. V. 2008. "Mechanical Properties of Carbon Fiber Reinforced Epoxy/Clay Nanocomposites." Composites Science and Technology 68 (3-4): 854-61. 